\title{
Atividade antitumoral in vitro de Prosopis juliflora frente a células cancerígenas do
}

\section{tipo melanoma}

\author{
In vitro antitumoral activity of Prosopis juliflora in front of melanoma type cancerogen cells \\ Actividad antitumoral in vitro de Prosopis juliflora frente a células cancerígenas tipo melanoma
}

Recebido: 20/03/2021 | Revisado: 01/04/2021 | Aceito: 05/04/2021 | Publicado: 15/04/2021

Giani Maria Cavalcante

ORCID: https://orcid.org/0000-0002-0143-3364 Instituto de Tecnologia de Pernambuco, Brasil

E-mail: gianimc@icloud.com

Patrícia Lira Barbosa

ORCID: https://orcid.org/0000-0002-4743-5971 Universidade Federal Rural de Pernambuco, Brasil

E-mail: patricialaiz@hotmail.com

Adrielle Antônia da Silva

ORCID: https://orcid.org/0000-0002-0784-3903 Centro Universitário Maurício de Nassau, Brasil

E-mail: patricialaiz@hotmail.com

\begin{abstract}
Resumo
O objetivo deste estudo foi investigar a atividade antitumoral de Prosopis juliflora contra células tumorais humanas da linhagem B16-F10 (melanoma) para buscar novos medicamentos derivados de fontes naturais. Testes in vitro foram conduzidos com os extratos brutos de folhas e de casca de caule frente às linhagens de células B16-F10 e linhagem de células J774 através do teste de citotoxicidade de MTT (3- (4,5-dimetiazol-2il) 2,5-difenil tetrazólio de brometo) com monitorização após 24 e $48 \mathrm{~h}$ de exposição das células tumorais e não tumorais a diferentes concentrações dos extratos $(100 ; 50 ; 25 ; 12,5 \mu \mathrm{g} / \mathrm{mL})$. O extrato de casca de caule e o extrato de folha de $P$. juliflora inibiram a proliferação de células B16-F10 a partir da menor concentração testada $12,5 \mathrm{Mg} / \mathrm{ml}$ e não apresentaram citotoxidade frente às células não tumorais. Entretanto, o extrato de folha de $P$. juliflora apresentou diminuição sobre a viabilidade celular de forma considerável a partir de $50 \mathrm{Mg} / \mathrm{ml}$. Sugere-se o estudo químico para extração e isolamento de compostos ativos oriundo dos extratos de folha e da casca de caule de $P$. juliflora, para investigar a possível atividade antitumoral destes compostos em ensaio in vitro e in vivo.
\end{abstract}

Palavras-chave: Atividade antitumoral; Melanoma; Produtos naturais; Prosopis juliflora.

\begin{abstract}
The aim of this study was to investigate the antitumor activity of Prosopis juliflora against human tumor cells of the B16-F10 lineage (melanoma) to search for new drugs derived from natural sources. In vitro tests were conducted with the crude extracts of leaves and stem bark against the tumor cell lines B16-F10 through the cytotoxicity test using MTT (3- (4,5-dimethiazol-2yl) 2,5-diphenyl tetrazolium of bromide) by monitoring after 24 and $48 \mathrm{~h}$ of exposure of tumor and non-tumor cells to different concentrations of the extracts $(100 ; 50 ; 25 ; 12.5 \mu \mathrm{g} / \mathrm{mL})$. The cytotoxicity tests were performed using non-tumor cells (macrophages lineage J744). The stem bark extract and the leaf extract of $P$. juliflora inhibited the proliferation of B16-F10 cells from the lowest tested concentration $12.5 \mathrm{Mg} / \mathrm{ml}$ and did not show cytotoxicity against non-tumor cells. However, $P$. juliflora leaf extract showed a considerable decrease in antineoplastic activity from $50 \mathrm{mg} / \mathrm{ml}$. It is suggested the chemical study for the extraction and isolation of active compounds from the extract of the leaves and stem bark of P. juliflora, and through testing these compounds in vitro and in vivo to investigate their possible antitumor activity.
\end{abstract}

Keywords: Antitumor activity; Melanoma; Natural products; Prosopis juliflora.

\section{Resumen}

El objetivo de este estudio fue investigar la actividad antitumoral de Prosopis juliflora contra células tumorales humanas del linaje B16-F10 (melanoma) para buscar nuevos fármacos derivados de fuentes naturales. Se realizaron pruebas in vitro con los extractos crudos de hojas y corteza de tallo contra las líneas celulares tumorales B16-F10 mediante la prueba de citotoxicidad utilizando MTT (bromuro de 3- (4,5-dimetiazol-2il) 2,5-difenil tetrazolio) monitoreo después de 24 y 48 h de exposición de células tumorales y no tumorales a diferentes concentraciones de los extractos $(100 ; 50 ; 25 ; 12,5 \mu \mathrm{g} / \mathrm{mL})$. Las pruebas de citotoxicidad se realizaron utilizando células no tumorales (linaje de macrófagos J744). El extracto de corteza de tallo y el extracto de hoja de $P$. juliflora inhibieron la proliferación de células B16-F10 a partir de la concentración más baja probada 12,5 Mg / ml y no mostraron citotoxicidad contra 
células no tumorales. Sin embargo, el extracto de hoja de $P$. juliflora mostró una disminución considerable en la actividad antineoplásica de $50 \mathrm{mg} / \mathrm{ml}$. Se sugiere el estudio químico para la extracción y aislamiento de compuestos activos del extracto de la corteza del tallo de P. juliflora, y mediante el ensayo de estos compuestos in vitro y in vivo para investigar su posible actividad antitumoral.

Palabras clave: Actividad antitumoral; Melanoma; Productos naturales; P. juliflora.

\section{Introduçãa}

O melanoma é um tumor cutâneo originário dos melanócitos, células responsáveis pela produção da melanina, podendo surgir em qualquer parte do corpo, como pele, orelhas, mucosas, na forma de manchas, pintas ou sinais. (Martins e Costa, 2020). Os principais fatores de risco para o desenvolvimento desse câncer incluem exposição à radiação ultravioleta (UV) cumulativa, queimaduras solares prévias, múltiplos nevos, fototipo cutâneo, histórico familiar, imunossupressão e fatores hereditários (Souza, Silva, Miyashiro, Kakizaki \& Valente, 2020).

Embora o câncer de pele represente $30 \%$ de todos os tumores malignos registrados no país, o melanoma representa apenas 3\% das neoplasias malignas desse órgão. Entretanto, é o tipo mais grave, devido seu alto potencial metastático, com difícil reversão prognóstica com o avanço da doença (Instituto Nacional do Câncer, 2020).

O tratamento para o melanoma incluí principalmente excisão cirúrgica, entretanto, a determinação da área afetada a ser retirada, bem como possíveis complicações clínicas e até estéticas, influenciam para a busca de tratamentos menos invasivos e que sejam eficazes. Devido ao grande potencial terapêutico das espécies vegetais, estas têm sido fonte para a produção de novos compostos terapêuticos a fim de serem utilizados contra uma variedade de doenças. Aproximadamente dois terços dos compostos anticancerígenos advêm de produtos naturais ou derivados destes (Amaria et al., 2019; Viana, Marzari, Wergutz \& Krause, 2017)

Dada a relevância do câncer como importante problema de saúde pública, sendo considerada a segunda causa de mortes na população mundial, com tendência de crescimento nos próximos anos, em especial os cânceres originados no tecido tegumentar, é essencial a pesquisa e desenvolvimento de novos agentes antitumorais, bem como mecanismos para sua avaliação em culturas de células tumorais, e assim selecionar compostos eficientes e seguros que possam ser utilizados no tratamento de neoplasias (Urban, Mehrmal, Uppal, Giesey \& Delost 2021).

Estratégias para amenizar ou reverter processos neoplásicos através da utilização de substâncias naturais ou derivadas sintéticas, emergiram como uma abordagem promissora no tratamento do câncer. A fauna brasileira possibilita uma infinidade de espécimes vegetais com potencial terapêutico que podem propiciar a descoberta de novas moléculas anticancerígenas mais eficazes e menos tóxicas. Nesta perspectiva, o presente trabalho teve como objetivo avaliar a atividade antitumoral do extrato hidroalcóolico das folhas e casca de caule da espécie vegetal Prosopis juliflora frente a células tumorais do tipo melanoma.

\section{Metodologia}

\section{Material vegetal e obtenção dos extratos de P. juliflora}

As folhas e cascas de caule de P. juliflora foram obtidas junto ao Viveiro Florestal da Universidade Federal Rural de Pernambuco (UFRPE) e a confirmação da espécie foi feita por profissionais botânicos do Herbário Professor Vasconcelos Sobrinho da UFRPE.

Todo material vegetal foi submetido a secagem em estufa a $50{ }^{\circ} \mathrm{C}$ até obter o teor padrão de $20 \%$ de umidade. Após a secagem, separadamente, folhas e caules foram triturados e o pó resultante acondicionados em vidros individuais, devidamente identificados.

Para a preparação do extrato de folha (EF) e do extrato de casca de caule (ECC), $100 \mathrm{~g}$ de pó foi misturado com em solução água: álcool etílico P.A 50\%, em Becker separados, e deixados em repouso por $72 \mathrm{~h}$ a $25{ }^{\circ} \mathrm{C}$ em local escuro. 
Transcorrido o tempo, a mistura foi filtrada e submetida a rotaevaporação sob vácuo a $30{ }^{\circ} \mathrm{C}$, até a evaporação total do solvente, obtendo-se os extratos EF e ECC. Estes foram acondicionados em frasco âmbar com identificação, estando prontos para uso nos ensaios de viabilidade celular.

\section{Obtenção e manutenção das células não tumorais e tumorais.}

As células não tumorais (macrófagos linhagem J744) e tumorais (Melanoma linhagem B16-F10) foram obtidas junto ao banco de células da Universidade Federal do Rio de Janeiro (BCRJ/UFRJ) e mantidas em meio de cultura Dulbecco's Modified Eagle Medium (DMEM) suplementado com 10\% de soro fetal bovino (SFB), 2mM de L-glutamina, 4,5 g.L.-1 de glicose, $1,5 \mathrm{~g} . \mathrm{L}^{-1}$ de bicarbonato de sódio, $100 \mathrm{~mL}$ de penicilina e estreptomicina e mantidas em incubadora a $37{ }^{\circ} \mathrm{C}$ e $5 \%$ de $\mathrm{CO}_{2}$. A manutenção foi feita regularmente.

\section{Ensaios de viabilidade celular de células não tumorais e tumorais.}

Os ensaios laboratoriais de viabilidade celular in vitro foram realizados de acordo com a Metodologia descrita por Costa e Cavalcante (2018). As células J744 e B16-F10, na densidade de 2,5 x $10^{3}$ células por poço, foram incubadas em placa de 96 poços contendo $100 \mu \mathrm{L}$ de DMEM suplementado com 10\% SFB, $2 \mathrm{mM}$ de L-glutamina, 4,5 g.L $\mathrm{L}^{-1}$ de glicose, 1,5 g.L $\mathrm{L}^{-1}$ de bicarbonato de sódio, $100 \mathrm{~mL}$ de penicilina e estreptomicina, em atmosfera contendo $5 \%$ de $\mathrm{CO}_{2}$ a $37^{\circ} \mathrm{C}$.

Transcorridas $24 \mathrm{~h}$ de incubação, o meio de cultura foi removido e as células foram tratadas com concentrações crescentes $(12,5-100 \mathrm{mg} / \mathrm{mL})$ dos extratos EF e ECC. Como controle positivo foi utilizado o fármaco padrão Trametib (2mg) e como controle negativo foi utilizado meio de cultura suplementado com SBF sem células. As placas foram incubadas por 48 $\mathrm{h}$ em atmosfera contendo $5 \%$ de $\mathrm{CO}_{2}$ a $37{ }^{\circ} \mathrm{C}$. Após o tempo de incubação, o sobrenadante foi removido dos poços e em cada poço foi adicionado $100 \mu \mathrm{L}$ de solução contendo $10 \mu \mathrm{L}$ de MTT (brometo de 3-[4,5-dimetil-tiasol-2-il]-2,5 difeniltetrazol) e 90 $\mu \mathrm{L}$ de DMEM, para examinar função mitocondrial das células viáveis. As placas foram mantidas sob ausência de luz durante 4 horas a $37^{\circ} \mathrm{C}$, em seguida, foi adicionado $200 \mu \mathrm{L}$ de DMSO em cada poço. A leitura da absorbância foi realizada em leitor de placa de ELISA a $550 \mathrm{~nm}$. Os valores de proliferação celular foram comparados com os valores dos poços com meio de cultura sem células (Controle negativo) e a análise estatística foi realizada através da análise de variância (ANOVA) seguida pelo te ste de Dunnet, utilizando o software BioEstat versão 5.0.

\section{Resultados e Discussão}

Os efeitos de diferentes concentrações do extrato de folha (EF) e extrato de casca de caule (ECC) de P. juliflora sobre a viabilidade de células não tumorais (Macrófagos J744) e células tumorais de melanoma B16-F10 são evidenciados nas Figuras 1 e 2, respectivamente. Células tratadas apenas com meio de cultura suplementado com SBF foram usadas como controle negativo (C-), enquanto células tratadas com meio de cultura e o fármaco padrão Trametib ( $2 \mathrm{mg}$ ) foram usadas com controle positivo $(\mathrm{C}+)$. 
Figura 1 - Efeitos de diferentes concentrações do extrato da folha (EF) de $P$. juliflora na proliferação de células não tumorais (Macrófagos J744) e tumorais B16-F10. O controle negativo (C-) corresponde às células tratadas apenas com meio de cultura com SBF e o controle positivo $(\mathrm{C}+)$ corresponde às células tratadas com o fármaco padrão, trametib (2mg). *Diferença estatística significativa em relação ao controle negativo.

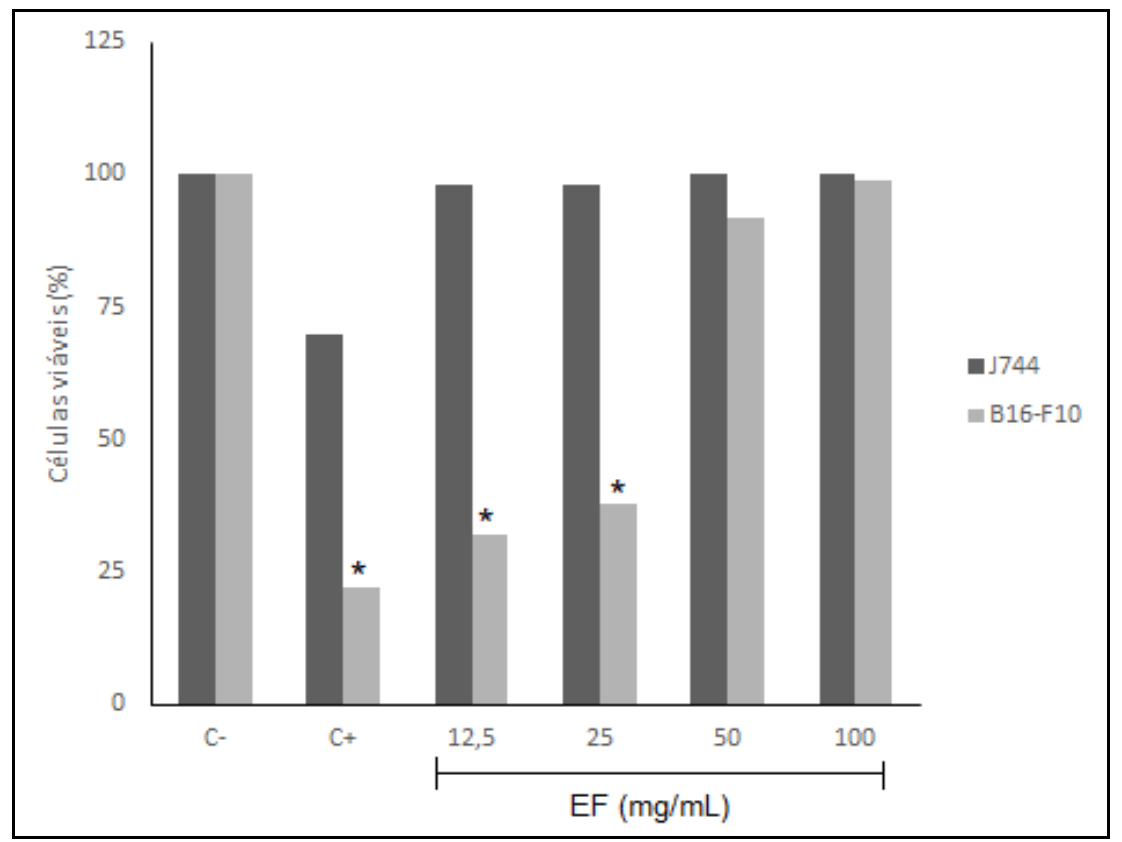

Fonte: Autores (2021).

Figura 2 - Efeitos de diferentes concentrações do extrato da casca do caule (ECC) de P. juliflora na proliferação de células não tumorais (Macrófagos J744). O controle negativo (C-) corresponde às células tratadas apenas com meio de cultura com SBF e o controle positivo $(\mathrm{C}+)$ corresponde às células tratadas com o fármaco padrão, trametib $(2 \mathrm{mg})$. *Diferença estatística significativa em relação ao controle negativo.

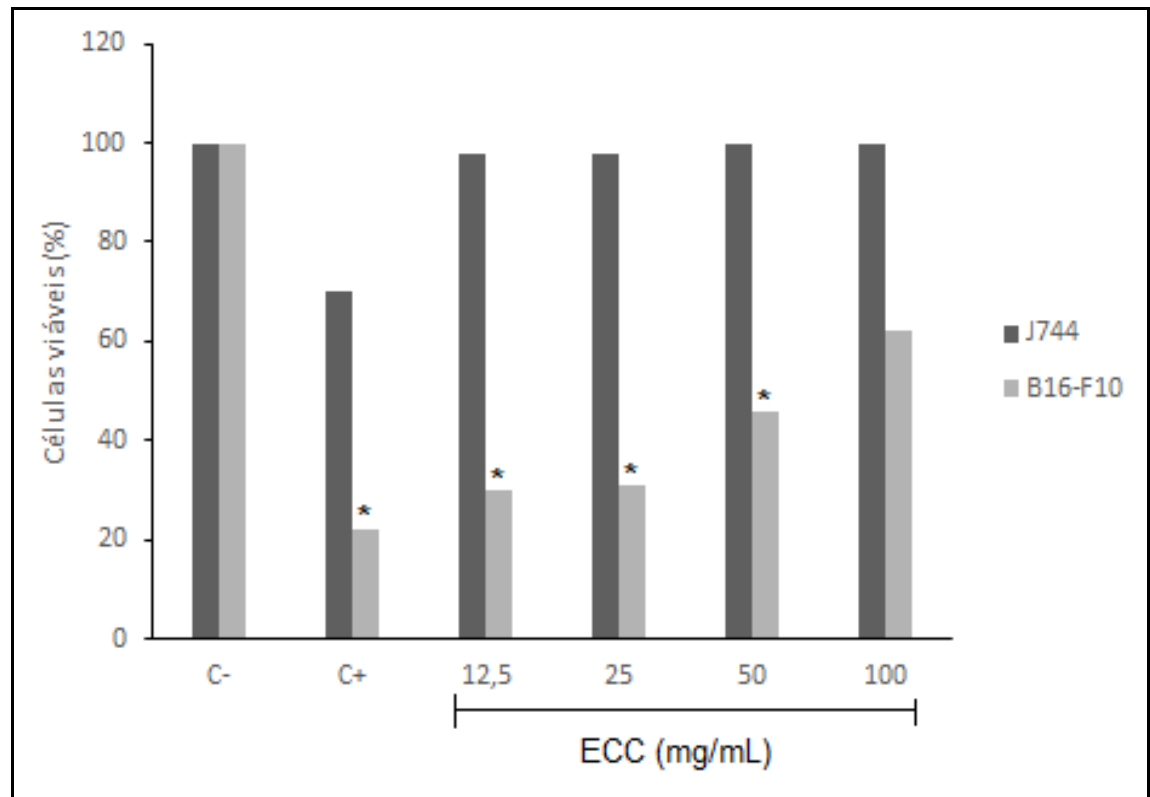

Fonte: Autores (2021). 
Nas Figuras 1 e 2, observa-se, a atividade antiproliferativa e possível citotoxicidade, do extrato da folha EF e o extrato da casca do caule ECC de P. juliflora que foram testados frente à linhagem B16-F10 e em células J744. Ambos os extratos, apresentaram atividade antitumoral a partir da menor concentração testada, $12,5 \mathrm{Mg} / \mathrm{ml}$. Os melhores resultados foram obtidos até a concentração de $25 \mathrm{mg} / \mathrm{mL}$ para o EF, e até $50 \mathrm{mg} / \mathrm{mL}$ para ECC, com os melhores percentuais de morte celular tumoral registrados para o extrato da casca do caule. Outro ponto essencial a ser observado nos gráficos acima é a ausência de efeitos citotóxicos dos extratos EF e ECC frente às células não tumorais J744.

Segundo Safe e Kasiappan (2016) utilização de espécimes vegetais no tratamento das mais diversas patologias, acompanha a humanidade. No Egito antigo, mil e quinhentos anos antes de cristo, já eram utilizados mais de 700 medicamentos de origem natural, de acordo com o livro "Eber Papyrus". De acordo com Kuruppu, Paranagama e Goonasekara (2019) por muitos séculos e até hoje, as culturas indígenas em todo o mundo se beneficiam da prática da medicina tradicional à base de ervas para tratar uma miríade de doenças, incluindo o câncer. Isso se deve ao potencial terapêutico dos constituintes fitoquímicos dos espécimes vegetais, que se apresentam como fonte em potencial para a elaboração de novos compostos (Aumeeruddy e Mahomoodally, 202; Dent e Matoba, 2020).

Um aspecto positivo da $P$. juliflora é sua abundância e adaptação a clima seco e com restrição de nutrientes. Trata-se de uma árvore tradicional ornamental, comum em regiões áridas e semiáridas, predominante em todos os estados do nordeste brasileiro. Apresenta rápido crescimento, resistência a seca e com elevado potencial energético, com diversas aplicações e usos em meio rural desde a antiguidade (Nascimento, 2017; Joung, et al., 2021).

Quimicamente, os frutos $P$. juliflora possuem diversos ativos como terpenoides, fenol, saponina e taninos com atividade farmacológica descrita em literatura (IBRAHIN et al., 2013; RICÓN et al., 2014; PREETI et at., 2017; Henciya et al., 2017). Com comprovada ação anticancerígena, apresenta compostos como Pentanal (nasofaringe), Butiramida (nasofaringe), ácido n-hexadecanóico (pâncreas, faringe, próstata, mama, pulmão) Genoplasto B (mama, pulmão, bexiga e próstata) (Malik, Ahmed, \& Khan, 2018).

Em comparação a ação de outros compostos naturais frente às células B16-F10 de melanoma, Carvalho (2013), determinou que a concentração letal média da própolis G6 baiana para essas células tumorais foi de $24,1 \mu \mathrm{g} / \mathrm{mLa}$. Em comparação com tal estudo, a p. juliflora apresentou atividade antitumoral a partir da menor concentração testada $12,5 \mathrm{mg} / \mathrm{ml}$, o que se demonstrou como um achado farmacológico promissor.

É preciso salientar, que de acordo com Yip et al. (2016), os efeitos citotóxicos das terapias anticâncer constituem um dos fatores limitantes a sua utilização. Foi evidenciado nas Figuras 1 e 2, que a tanto o EC quanto o ECC da $P$. juliflora não apresentaram ação frente às células normais. Em comparação com a droga padrão utilizada para tratamento da doença, o Trametib, que inviabilizou em aproximadamente $30 \%$ as células não cancerígenas. Essa ausência de citotoxicidade em células normais, em associação a ação antitumoral demonstrada a partir da menor dose testada, como evidenciado nas Figuras 1 e 2, demonstraram que a $P$. juliflora como um potencial recurso para obtenção de substâncias isoladas a serem testadas em ensaios de atividade antitumoral.

A prospecção de novos compostos extraídos de vegetais já é uma realidade no tratamento de diversos cânceres. Dada à relevância clínica e agressividade do melanoma, os resultados obtidos da $P$. juliflora frente a essas células cancerígenas apresentadas nessa pesquisa, reforçam a necessidade de novos estudos e ensaios que resultem numa possível inovação tecnológica para produção farmacêutica de novas moléculas antitumorais.

\section{Conclusão}

O extrato ECC de $P$. juliflora apresentou os melhores resultados e inibiu a partir da menor concentração testada (12,5 $\mathrm{mg} / \mathrm{mL}$ ), a proliferação celular da linhagem B16-F10. O extrato da folha de $P$. juliflora inibiu a partir da menor concentração 
testada $(12,5 \mathrm{mg} / \mathrm{mL})$ a proliferação celular da linhagem B16-F10, entretanto, com diminuição da atividade antineoplásica de forma considerável a partir de $50 \mathrm{Mg} / \mathrm{ml}$. Ambos os extratos, ECC e EF não apresentaram toxicidade frente a células J744, sugerem-se estudos de atividade antitumoral de compostos isolados a partir desses extratos.

\section{Agradecimentos}

FACEPE - Fundação de Amparo à Ciência e Tecnologia do Estado de Pernambuco, pelo financiamento da pesquisa.

\section{Referências}

Amaria, N. R., Menzie, A. M., Burton, E. M., Scolyer, R. A., Tetzlaff, M. T., Antdbacka, R., Ariyan, C., Bassett, R., Carter, B., Daud, A., Faries, M., Fecher, L. A., Flaherty, K. T., Gershenwald, J. E., Hamid, O., Hong, A., Kirkwood, J. M., Lo, S., Margolin, K., Messina, J., Michael, A. P., M. A., Rizos, H., Ross, M. I., Saw, E. A. R. R. P.M., Sondak, V., Sullivan, R. J., Taube, J. M., Thompson, J. F., Wiel, B. A. V. W. \& Eggermont, A. M. (2019). Neoadjuvant systemic therapy in melanoma:recommendations of the International Neoadjuvant Melanoma Consortium. Lancet Oncology. 20, 7, 378-389.

Aumeeruddy, M. Z., \& Mahomoodally, M. F. (2021). Global documentation of traditionally used medicinal plants in cancer management: A systematic review. South African Journal of Botany, 138, 5, 424-494.

Brasil. Ministério Da Saúde. Instituto Nacional De Câncer José Alencar Gomes Da Silva (2020). Coordenação de Prevenção e Vigilância. Estimativa 2020: incidência de câncer no Brasil. INCA.

Carvalho, N. C. (2013). Avaliação da atividade antineolpásica do extrato etanólico da própolis G6 baiana. Dissertação de Mestrado, Centro de Pesquisas Gonçalo Moniz, Fiocruz, Salvador, BA, Brasil.

Costa, A. C. F. \& Cavalcante, G. M. (2018). Atividade antitumoral in vitro de Prosopis juliflora frente a células tumorais de câncer de mama e câncer de ovário. Acta Biomedica Basiliensia, 9,1, 131-135.

Dent, M. \& Matoba, N. (2020). Cancer biologics made in plants. Current Opinion in Biotechnology, 61, 2, 82-88.

Henciya, S., Seturaman, P., James, A. R., Tsai, Y. H., Nikam, R., Wu, Y. C., Dahms, H. U. \& Chang, F. R. (2016). Biopharmaceutical potentials of Prosopis spp. (Mimosaceae,Legume). Journal of Food and Drug Analysis, 30, 1, 1-10.

Ibrahim, M., Nadir, M. \& Ali, A. (2013). Phytochemical analyses of Prosopis juliflora Swartz D.C. Pakistan Journal of Botany, 45, 2, $20101-2104$.

Joung, J. H., Hwang, J., Kim, J. H., Sim, Deok, Y. Si., Im, E., Parque, J. E, Parque, W. Y., Shim, B. S., Kim, B. \& Kim, S. H. (2021). Phyotochemical candidates repurposing for câncer therapy and their molecular. Seminars in Cancer Biology, 68, 1, 164-174.

Kuruppu, A. L., Paranagama, P. \& Goonasekara, C. (2019). Medicinal plants commonly used against cancer in traditional medicine formula in Sri Lanka. Saudi Pharmaceutical Jornal. 27, 4, 565-573.

Malik, S. K., Ahmed, M. \& Khan, F. (2018). Identification of new anticancer terpenoids from Prosopis juliflora (Sw) DC pods (Leguminosae). Tropical Journal of Pharmaceutical Research, 17, 4, 661-668.

Martins, C. C. \& Joung, J. H., Hwang, J., Kim, J. H., Sim, Deok, Y. Si., Im, E., Parque, J. E, Parque, W. Y., Shim, B. S., Kim, B. \& Kim, S. H. (2021). Phyotochemical candidates repurposing for câncer therapy and their molecular. Seminars in Cancer Biology, 68, 1, $164-174$.

Costa, M. M. (2020). Fatores de risco de melanoma em uma população latino-americana. Anais Brasileiros de Dermatologia, 95, 4, 529-531.

Nascimento, M. P. M. (2017). Potencial acaricida do extrato aquoso de algarobeira Prosopis juliflora no controle do ácaro Tetranychus bastosi na cultura do pinhão-manso. Dissertação de Mestrado, Serra Talhada, PE, Brasil.

Pretti, K., Sharma, R. A. \& Acarwal, M. (2017). Isolation and identification of flavonoids from Prosopis juliflora. Mintage Journal of Pharmaceutical and Medical Sciences, 6, 1, 1-3.

Ricón, F., Muñoz, J. \& Ramirez, P. (2014). Physicochemical and rheological characterization of Prosopis juliflora seed gum aqueous dispersions. Food Hydrocoll , 35, 1, 357-357.

Safe, S. \& Kasiappan, R. (2016). Natural products as Mechanism-based anticancer agents: Sp. transcription factors as targets. Phytotherapy Research, 30, 11, $1723-1732$

Souza, B. C., Silva, D. H. M., Miyashiro, D., Kakizaki, P. \& Valente, N. Y. S., (2020). Clinical-pathological analysis of acral melanoma in a single center: study of 45 cases. Revista da Associação Médica Brasileira,6,10, 1391-1395.

Urban, K., Mehrmal, S., Uppal P., Giesey, R. L. \& Delost, G. R. (2021). The global burden of skin cancer: a longitudinal analysis of the Global Burden of Disease Study, 1990-2017. JAAD International, 2,3, 98-108.

Vedak S. \& Raut S.V. (2014). Estudo de compostos antibacterianos do extrato metanólico da casca de Prosopis juliflora (Vilayati babhul). International Journal Pharmaceutical Science Business Management 2014; 2: 1-14.

Viana, A. R., Marzari, J., Wergutz, J. \& Krause, L. M. F. (2017). Produtos bioativos na prevenção e no tratamento do Câncer, em especial o melanona. Disciplinarum Scientia, 18, 3, 511-528. 
Research, Society and Development, v. 10, n. 4, e39510414095, 2021

(CC BY 4.0) | ISSN 2525-3409 | DOI: http://dx.doi.org/10.33448/rsd-v10i4.14095

Yip, K. T., Zhong, Y. Z., Putz, N. S. S., Autzen, J., Gasper, R., Hofmann, E., Scherkenbeck, J. \& Stoll, R. (2016). Small molecules antagonize the MIAFibronectin interaction in malignant melanoma. Scientific Reports, 6, 25119, 1-12. 